\title{
Studies on the Diffractometric Measurement of the Diameter of Erythrocytes.
}

\section{Accuracy of diffractometric method of Haden-Haus ser's erythrocytometer in cases of blood without pathological anisocytosis.}

By

Kōjirō Matsuda.

(松画幸次䬦)

(Department of Physiology, Tokyo Imperial University. Department of Medicine, St. Luke's Hospital, Tokyo.)

\section{INTRODUCTION.}

Although the sizes of erythrocytes of man and other animals have been measured since long ago, it is comparatively recently that its significance has become known. Not only for the diagnosis and treatment of anemias, but also for almost any hematological research, it is now considered to be indispensable to measure the size of erythrocytes as an indicator of the hemopoietic activity. Besides, it has been reported that erythrocytes change sizes in vivo according to changes in the physicochemical condition of the blood, a very interesting fact which should be investigated further. Also their macrocytic tendency in cases with damage to the liver and the spleen is full of suggestion from the physiological standpoint.

Numerous valuable investigations have been reported concerning: the measurement of the diameter of erythrocytes, but in almost all cases the methods used were either the direct measurement of each red cell under the microscope or the measurement of photomicrographs of the cells. Both procedures require much time and effort even after one has become experienced in the methods. However, the diffractometric method of measurement is recommended to give the value of the mean diameter of a large number of erythrocytes at a glance with little effort. The theory of this method is well discussed by Miller, ${ }^{10)}$ Allen and Ponder, ${ }^{1)}$ Pijper ${ }^{15)}$ and Bergansius. ${ }^{2)}$ 
Several instruments for this purpose have been described to be

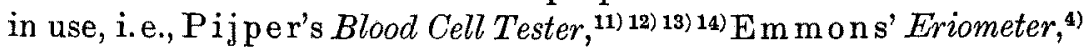
Eve's Halometer, ${ }^{5)}$ Bock's ${ }^{3)}$ and Haden's' Erythrocytometer. The last mentioned device was introduced by $\mathrm{Haden}$ to have the advantage of greater accuracy and less expensiveness. In his original article he gave some data of measurements using his erythrocytometer, but it seemed to me the accuracy of this method was not discussed sufficiently and critically. Therefore, I tried to test to what extent this method will give accurate results for the measurement of the mean diameter of erythrocytes compared with the direct method of measurement. Some investigators have already performed such critical studies using one of the apparatus mentioned above and their opinions seem to agree in acknowledging some advantage in the use of the diffractometric method.6) 8) 9) 16) 17) 18) 19)

\section{Preparation of Blood Samples.}

Wet preparations of erythrocytes in the blood plasma of the same individual are thought to be the best, as this is the condition most similar to that which is found in the body. But some difficulties arise, if one tries to do the direct measurement with such preparations under microscope, as cells in the plasma shift very easily on slightest manipulation of the microscope. Therefore, I used dried smear, stained with Giemsa's solution.

The blood obtained from human finger tip or rabbit's ear was spread evenly and dried as quickly as possible. The smear was fixed in methyl alcohol for 3 minutes and then stained with Grübler's Roman ow sky-Giemsa's staining solution (1 drop of the dye in $1 \mathrm{cc}$ of dilute phosphate buffer mixture of $1 / 150 \mathrm{~mol}$. and of $\mathrm{pH}$ cir. 6.5) for exactly 10 minuts, washed with distilled water and dried.

\section{Direct Measurement with Filar Micro- METER EyEPIECE.}

Leitz's microscope with the objective "Homogene Immersion, n. A. : $1.3, \times 100 "$ and Leitz's filar micrometer eyepiece $\times 10$ were used. The light source was an ordinary 60 watt electric lamp, the light was made to pass through alkaline copper sulphate solution which was placed between the light source and the microscope.

As the standard of micrometry, Zeiss' object micrometer was 
employed. Each interval of scales is given to correspond to $10 \mu$. As to its accuracy no special test was performed and I only relied upon its exactness. If the tube length was kept to be $13 \mathrm{~cm}$, the least scale interval on the drum of the filar micrometer was found to correspond to $0.050 \mu$, and therefore, it was very easy to read off directly the diameter of erythrocytes in $\mu$.

As the result of preliminary test of measuring repeatedly the diameter of the same cell in the same direction, I found the probable error of each measurement was of the order of $0.05 \mu$. The average of the two readings was taken as the value.

Of each slide a portion was selected where the cells were well distributed and where no overlapping or deformity of cells occurred. This portion was marked and was used for both the direct and diffractometric measurements. For the diffractometric method, the selected portion should have an area of about $2 \times 2 \mathrm{~cm}$. Every slide having no suitable portion for measurement was discarded.

In each slide the diameter of 200 cells were measured, and the arithmetical mean of these 200 diameters was calculated with its probable error (P.E.). To show the degree of anisocytosis, PriceJones' curve is most satisfactory, but as the numerical expression of it the probable error of the mean diameter may be used.

According to my experience this P.E. was usually less than $0.03 \mu$ in the blood of healthy individual. Therefore, I regarded all blood specimens with the value of $\mathrm{P}$. E. of the mean diameter not exceeding $0.03 \mu$ as the blood sample with the physiological anisocytosis and treated them alike, whether they be microcytic or macrocytic.

To test the accuracy of the diffractometer per se, the results of measurement by the direct and diffractometric methods on blood samples with the physiological anisocytosis were compared, as the pathological anisocytosis often tends to make the diffractometric measurement difficult.

\section{Diffractometric Measurement.}

As to the details of Haden-Hausser's erythrocytemeter, the original article ${ }^{7)}$ may be consulted. It consits of double cylinders (internal I and external $\mathrm{E}$ in Fig. 1) and a light source (an electric bulb L) on the bottom of the cylinders. Above this light source there is a diaphragm (D) with a small central aperture and 3 sets of pinholes ( $a, b$ und $c$ in Fig. 2). The external cylinder can be slided up and 
Fig. 1. Diagram showing the construction of Had en-H a us ser's erythrocytometer.

C: Cover with slot.

E : External oylinder.

I : Internal eylinder.

D : Diaphragm.

L : Light source.

$\mathrm{H}$ : As described in the text.
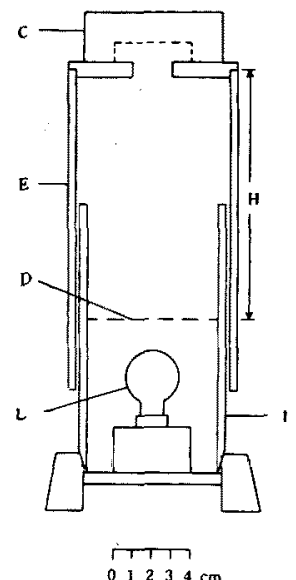

Fig. 2. Surface view of the diaphragm.

a: The inner set of holes.

b: The intermediate set of holes.

c: The outer set of holes.

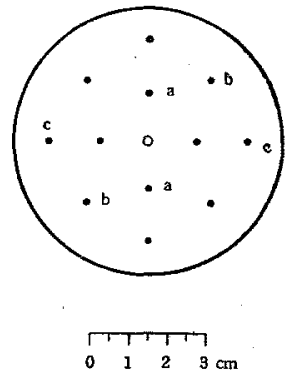

down along a vertical axis with rack and pinion. A blood slide is placed on the external cylinder and the distance $(\mathrm{H})$ between this slide and the diaphragm can be altered by moving the external cylinder. When viewed from above, we see a spectrum of colored rings arranged concentrically to a central white light. These colored rings change their sizes with the change of the distance H. Haden suggested to use blood smears stained by Wright's method and mounted in the normal saline solution and to adjust this distance so as to make the inner red ring coincide with the inner set of small apertures (a), and the distance $\mathrm{H}$ can be read by a scale on a hand wheel, which moves the external cylinder, in terms of microns. This value is adopted to show directly the mean diameter of erythrocytes of the specimen. It is also described that two other sets of apertures ( $b$ and c) may be used similarly with the yellow and the outer red rings respectively.

However, I used specimens stained by Giemsa's method as I described above and measured the dried as well as wet (mounted in normal saline) smears. And on diffractometry I took three sets of readings by making coincide (1) the inner red ring with the inner set of holes, (2) the yellow ring with the intermediate set of holes and (3) the outer red ring with the outer set of holes. The reading is the average of 5 individual readings. Tab. 1 is to show an example of differences in such individual readings and to show the error of the average. The least scale interval of the diffractometer is 0.2 , but the average was expressed to the second decimal place as its P.E. is 0.017 . 
TABLE 1.

Difference of 10 individual readings on the same smear of blood of a healthy man, the diffractometry in dried condition.

\begin{tabular}{|c|c|c|c|}
\hline $\begin{array}{c}\text { Colored ring } \\
\text { of } \\
\text { of readingloyed }\end{array}$ & $\begin{array}{l}\text { Adjusting with } \\
\text { the yellow ring }\end{array}$ & $\begin{array}{l}\text { Adjusting with } \\
\text { the outer red ring }\end{array}$ & $\begin{array}{l}\text { Adjusting with } \\
\text { the inner red ring }\end{array}$ \\
\hline $\begin{array}{r}1 \\
2 \\
3 \\
4 \\
5 \\
5 \\
6 \\
7 \\
8 \\
9 \\
10\end{array}$ & $\begin{array}{l}8.10 \\
8.20 \\
8.20 \\
8.10 \\
8.22 \\
8.10 \\
8.20 \\
8.22 \\
8.20 \\
8.10\end{array}$ & $\begin{array}{l}7.70 \\
7.80 \\
7.80 \\
7.82 \\
7.70 \\
7.75 \\
7.70 \\
7.65 \\
7.70 \\
7.70\end{array}$ & $\begin{array}{l}6.95 \\
6.90 \\
6.80 \\
6.80 \\
6.90 \\
6.80 \\
6.90 \\
6.75 \\
6.85 \\
6.90\end{array}$ \\
\hline Average ............ & 8.16 & 7.73 & 6.86 \\
\hline \multirow[t]{2}{*}{$\begin{array}{l}\text { The P. E. of each } \\
\text { individual reading }\end{array}$} & 0.038 & 0.038 & 0.042 \\
\hline & Average & 0.039 & \\
\hline
\end{tabular}

The P. E. of the average of 5 readings. $\quad 0.039 \times \frac{1}{\sqrt{5}}=0.017$

\section{Result of Measurement.}

By direct measurements with the filar micrometer eyepiece, I found that almost all values of erythrocytes of normal adults usually lie between 7.5 and $8.0 \mu$. To test the accuracy of this apparatus beyond the above mentioned range, blood specimens of unusually large . or small mean diameter but without pathological anisocytosis were necessary. Blood specimens of macrocytic or microcytic anemias are not suitable because of usually existing marked anisocytosis. Fortunately some of the macrocytic bloods of the patients suffering from liver damages (cancer or cirrhosis) were found to be without marked anisocytosis. For the microcytic range rabbit's blood was found to be adequate. Therefore, I selected 25 blood specimens from healthy men, from patients with liver damage and from rabbits, all having the P. E. of the mean diameter not exceeding $0.03 \mu$, and compared the values obtained by the direct measurement with the readings of the diffractometer.

Diffractometry of these 25 samples were done with dried slides, 
15 of them were also measured mounted in saline solution according to Ha de n's original method.

The results are presented in Table 2 and Fig. 3 and Fig. 4.

TABLE 2.

Comparison of the direct and diffractometric measurements on 25 blood samples without pathological anisooytosis. a : to be seen in the text. * Rabbit's blood. + Blood of patients with liver damage.

\begin{tabular}{|c|c|c|c|c|c|c|c|}
\hline \multirow{3}{*}{$\begin{array}{l}\text { No. of } \\
\text { specimen }\end{array}$} & \multirow{3}{*}{$\begin{array}{c}\text { Direct } \\
\text { measur. } \\
\mu\end{array}$} & \multicolumn{6}{|c|}{ Diffractometric measurement (Reading) } \\
\hline & & \multicolumn{3}{|c|}{ Stained and dried } & \multicolumn{3}{|c|}{$\begin{array}{l}\text { Stained and mounted } \\
\text { in saline }\end{array}$} \\
\hline & & Yellow & $\begin{array}{l}\text { Outer } \\
\text { red }\end{array}$ & $\begin{array}{l}\text { Inner } \\
\text { red }\end{array}$ & Yellow & $\begin{array}{l}\text { Outer } \\
\text { red }\end{array}$ & $\begin{array}{l}\text { Inner } \\
\text { red }\end{array}$ \\
\hline 1 & 8.36 & 8.76 & 8.45 & 7.75 & & & \\
\hline 2 & 8.01 & 8.50 & 7.97 & 7.11 & 8.52 & 8.31 & 7.57 \\
\hline 3 & 7.95 & 8.50 & 7.95 & 7.05 & & & \\
\hline 4 & 7.65 & 8.13 & 7.71 & 6.70 & & & \\
\hline 5 & 8.05 & 8.49 & 7.92 & 6.90 & & & \\
\hline 6 & 7.81 & 8.27 & 7.84 & 6.85 & & & \\
\hline $7+$ & 8.79 & 9.35 & 8.72 & 7.82 & 9.35 & 9.02 & 8.25 \\
\hline 81 & 8.24 & 8.77 & 8.21 & 7.01 & 8.67 & 8.40 & 7.53 \\
\hline 9 & 7.63 & 8.10 & 7.62 & 6.89 & 8.10 & 7.83 & 7.24 \\
\hline 10 & 7.99 & 8.42 & 7.87 & 7.01 & 8.35 & 8.12 & 7.37 \\
\hline 11 & 7.86 & 8.31 & 7.95 & 6.93 & & & \\
\hline $12 \dagger$ & 8.52 & 8.88 & 8.54 & 7.81 & & & \\
\hline $13^{*}$ & 6.67 & 7.05 & 6.60 & 5.78 & 7.05 & 6.86 & 6.13 \\
\hline $14 \dagger$ & 9.25 & 9.82 & 9.21 & 8.38 & 9.78 & 9,47 & 8.82 \\
\hline 15 & 7.82 & 8.24 & 7.79 & 6.88 & 8.28 & 8.01 & 7.48 \\
\hline 16 & 7.76 & 8,22 & 7.71 & 6.75 & 8.26 & 8.00 & 7.31 \\
\hline 17 & 8.01 & 8.55 & 7.86 & 7.08 & 8.50 & 8.30 & 7.51 \\
\hline 18 & 8.54 & 8.06 & 7.54 & 6.75 & 8.13 & 7.95 & 7.18 \\
\hline $19 \dagger$ & 8.37 & 8.72 & 8.21 & 7.22 & 8.71 & 8.51 & 7.90 \\
\hline 20 & 7.78 & 8.34 & 7.76 & 6.81 & 8.31 & 8.07 & 7.32 \\
\hline 21 & 7.85 & 8,19 & 7.70 & 6.89 & 8.19 & 8.07 & 7.31 \\
\hline 22 & 7.73 & 8,15 & 7.66 & 6.65 & & & \\
\hline 23 & 7.87 & 8.28 & 7.93 & 7.08 & & & \\
\hline 24 & 7.63 & 8.02 & 7.73 & 6.68 & & & \\
\hline $25 *$ & 6.85 & 7.24 & 6.75 & 5.84 & 7.18 & 6.98 & 6.29 \\
\hline $\mathbf{a}$ & & 0.946 & 1.004 & 1.126 & 0.945 & 0.973 & 1.067 \\
\hline
\end{tabular}

Discussion.

From these data, it is clear that the values obtained by the diffractometry and direct measurement show a satisfactory linear relationship, whichever colored ring (the inner red, the yellow or the outer red ring) one may use on diffractometry. If $y$ is taken as the value obtained by direct measurement and $x$ as that by diffractometry, we may write $y=\mathbf{a} x$, where $\mathbf{a}$ changes according to the colored ring used 
Fig. 3. The relationship between the values obtained by the direct and diffractometric methods on specimens of blood without pathological anisocy: tosis; diffractometry in dried condition.

Abscissa : Mean diameter in $\mu$ by direet measurement. Ordinate: Diffractometric reading.

O........Adjusting with the yellow ring.

O.........Adjusting with the inner red ring.

-.........Adjusting with the outer red ring.
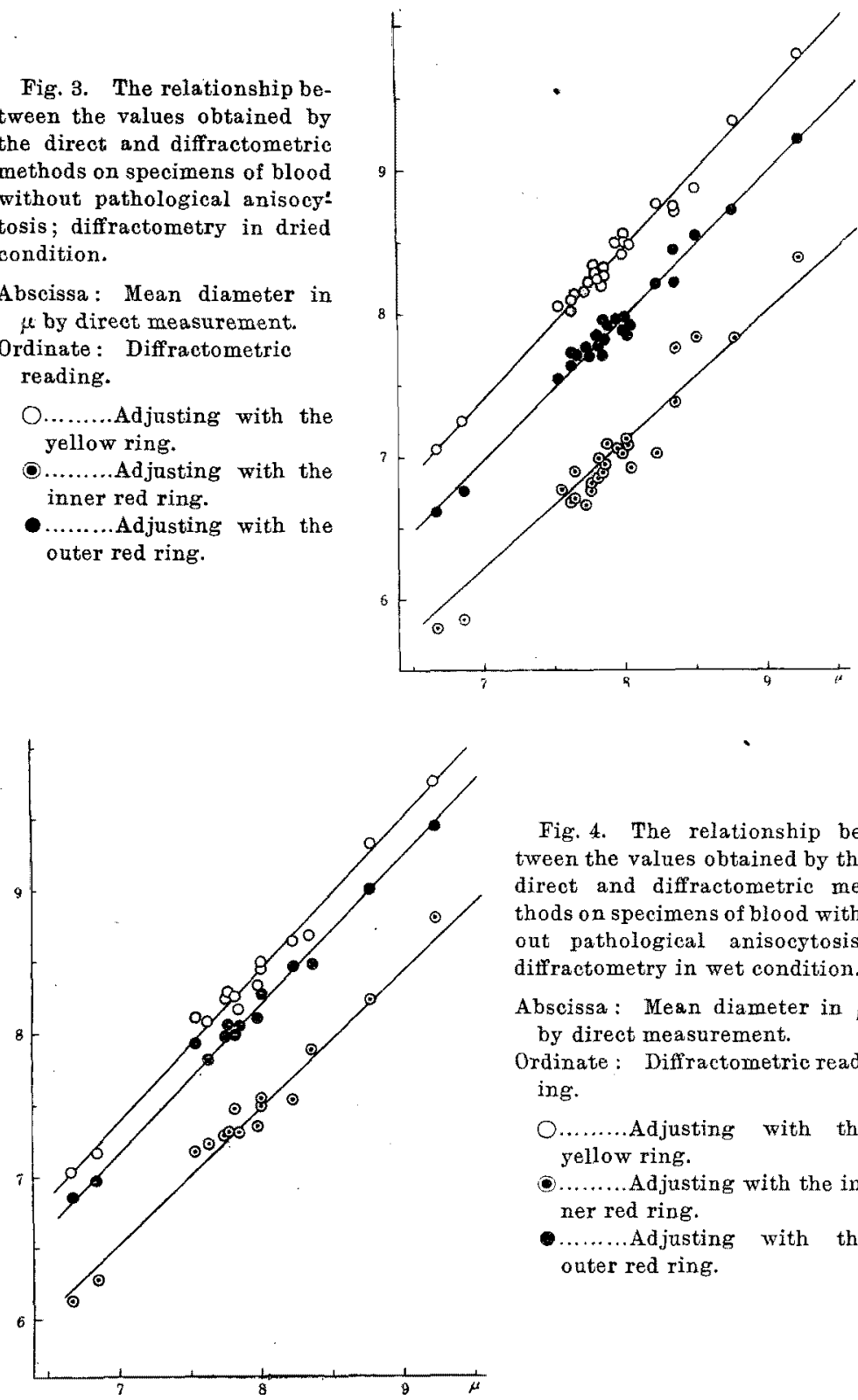

Fig. 4. The relationship between the values obtained by the direct and diffractometric methods on specimens of blood without pathological anisocytosis; diffractometry in wet condition.

Abscissa: Mean diameter in $\mu$ by direct measurement.

Ordinate: Diffractometric reading.

O........Adjusting with the yellow ring.

C........Adjusting with the inner red ring.

-........Adjusting with the outer red ring.

for measurement. For example, a for the yellow ring obtained by the least square method was 0.95 , both for dried and wet specimens; 
and taking errors into consideration I found the following equation:

$$
\text { where } \begin{aligned}
& y=\mathbf{a} x \pm 0.04 \mu, \\
& \mathbf{a}=0.95 \pm 0.01 .
\end{aligned}
$$

The values obtained with the inner and the outer red rings give both almost similar relation.

Here I want to mention two peculiar facts: (1) The values of diffractometry I obtained using the inner red ring with specimens mounted in saline solution did not show the mean diameter directly in $\mu$ as $\mathrm{Haden}$ claims, although they are proportional to the true mean diameter. (2) When using either of the red rings, a definite difference in the value of $\mathbf{a}$ in $y=\mathbf{a} x$ was noted depending on the specimen whether it was dry or mounted in saline solution, but almost no difference was noted if the yellow ring was used.

At any rate, I may conclude that $\mathrm{Had}$ en-Ha u s ser's erythrocytometer can be used for determination of the mean diameter of erythrocytes with the maximum error not exceeding $0.2 \mu(5 \times 0.04 \mu)$. Not only slides mounted in saline solution as $\mathrm{Haden}$ recommended but also dried slides can be used with the same degree of accuracy.

\section{Summary.}

(1) With 25 blood slides of man and rabbit without unusually marked anisocytosis, the mean diameter of erythrocytes was measured both with the filar micrometer eyepiece and Haden-Hausser's erythrocytometer, and the values by these two methods were compared.

(2) The error of Haden-Hausser's erythrocytometer was less than $0.2 \mu$ in the range covering from 6.5 to $9.5 \mu$.

(3) Taking the ease and simplicity of the procedure into consideration the error $0.2 \mu$ is relatively insignificant, and this apparatus can be used for the estimation of the mean diameter of erythrocytes with profit.

\section{References.}

(1) Alle n, A. and E. Ponder, Journ. Physiol., 1928, 66, 37.

(2) Bergansius, F. L., Ffiugers Arch., 1921, $192,37$.

(3) Bock, H. E., Klin. Wochensch., 1933, 1141.

(4) Emmons, W. F., Quart. Journ. Med., 1927, 21, 83. 
(5) Eve, F. C., Brit. Med. Journ., 1929-II, 48.

(6) H a d e n, R. L., Journ. Lab. \& Clin. Med., 1938, 23, 508.

(7) Haden, R. L., Journ. Lab. \& Clin. Med., 1940, 25, 399.

(8) L u ckner, H and F. Tilg er, Ztsch. f. gesamt. exper. Med., 1936, 99, 126.

(9) M a ye r, G., Ztsch. f. gesamt. exper. Med., 1940, 108, 261.

(10) Miller, W. G., Proc. Roy. Soc. London, B., 1926, 99, 265. 1935).

(11) Pijper, A., Med. Journ. South Africa, 1918, 14, 211. (Referred by Pijper,

(12) Pijper, A., Med. Journ. South Africa, 1919, 14, 472. (Referred by Pijper, 1935).

(13) Pijper, A., Lancet, 1924, 207, 367.

(14) Pijper, A., Brit. Med. Journ., 1929-I, 635.

(15) Pijper, A., Lancet, 1935, 228, 1152.

(16) Pryce, D. M., Lancet, 1929, 217, 275.

(17) Schmidt-Lange, W., Ztsch. f. gesamt. exper. Med., 1937, 10, 275.

(18) Sharp, E. A. and Schleicher, Journ. Lab. \& Clin. Med., 1936, 21, 975.

(19) Smith, K. E., Journ. Lab. \& Clin. Med., 194 I, 26, 696. 